\title{
LA INVERSIÓN DE LAS DINÁMICAS DE MIGRACIÓN INTERNA EN EL PERÚ POR LA COVID- 19 COMO LUGAR ÉTICO-TEOLÓGICO
}

\section{The Reverse Dynamics of Internal Migration in Peru Due to Covid-19 as an Ethical-Theological Place}

\author{
Juan Miguel Espinoza Portocarrero \\ Pontificia Universidad Católica del Perú \\ Lima - Perú \\ https://orcid.org/0000-0001-9813-9833 \\ jmespinozap@pucp.pe
}

\section{RESUMEN}

Entre los múltiples impactos de la pandemia de la COVID-19 en el Perú, resalta el éxodo de miles de ciudadanos, que, durante los primeros meses del confinamiento social en 2020, retornaron desde Lima a sus lugares de origen, debido a la imposibilidad de sobrellevar las medidas de cuarentena sin empleo o redes de soporte. Este artículo, reflexiona sobre las implicancias éticas y teológicas de este fenómeno, interpretando la inversión de las tendencias de migración interna en el Perú como un locus para entender la violencia sistémica del actual sistema político-económico, problematizar las deudas pendientes y los legados coloniales, y reconocer las prácticas de supervivencia y solidaridad creadora de sus víctimas. La experiencia de estas víctimas-sobrevivientes es un lugar desde donde imaginar un horizonte ético-político alternativo para el Perú del bicentenario y un discurso teológico comprometido con una praxis histórica de cambio social sustantivo y solidaridad con los oprimidos.

Palabras clave:

COVID 19, Migración interna, Desplazamiento forzado, Prácticas de resistencia

\begin{abstract}
Among the multiple impacts of the COVID-19 pandemic in Peru, the exodus of thousands of citizens stands out. During the first months of social confinement in 2020, they returned from Lima to their places of origin due to the impossibility of coping with quarantine measures without employment or support networks. This article reflects on this social phenomenon's ethical and theological implications, interpreting the reversal of internal migration trends in Peru as a locus to understand the systemic violence of the current political-economic system, to recognize the practices of survival and creative solidarity of their victims, and to problematize pending debts and colonial legacies. The experience of these victims-survivors is a place from which to imagine an alternative ethical-political horizon for a Bicentennial Peru and a theological discourse committed to a historical praxis of substantive social change and solidarity with the oppressed.
\end{abstract}

\section{Keywords:}

COVID-19, Internal migration, forced displacement, practices of resistance 


\section{INTRODUCCIÓN}

El Perú tiene el penoso récord de ser el país con más muertos de COVID-19 por cien mil habitantes, habiendo alcanzado los 197,879 fallecidos al 22 de agosto de 2021, según cifras oficiales del gobierno peruano. ${ }^{1}$ La magnitud con que el virus ha impactado a esta nación sudamericana se explica por las insuficiencias del Estado, las enormes y múltiples brechas de desigualdad socioeconómica, el alto nivel de economía informal, el hacinamiento de las viviendas populares y la debilidad del tejido social peruano (Arroyo, 2020; Comité de Alto Nivel sobre el COVID-19, 2021; Seminario et al., 2020). Semejante tragedia ha puesto en entredicho la narrativa del "milagro peruano", que celebraba el éxito económico post-caída de la dictadura de Alberto Fujimori (1990-2000) y la consolidación de un modelo neoliberal en democracia durante las últimas dos décadas (Taj E Kurmanaev, 2020; Vergara, 2020). La pandemia, por tanto, coloca al Perú en una crisis estructural que demanda una reconstrucción sociopolítica del país y nuevas narrativas históricas para repensar los fundamentos de esta comunidad nacional de cara a la conmemoración del bicentenario de la creación de la República peruana.

En su última encíclica, el papa Francisco da una pista fundamental para imaginar y re-narrar la reconstrucción del mundo post-pandemia: "si hay que volver a empezar, siempre será desde los últimos" (FT 235). En este ensayo, reflexiono sobre las implicancias éticas y teológicas de este planteamiento desde el Perú fracturado por la crisis sanitaria, económica y política. Tal perspectiva no es una novedad en el país desde donde Gustavo Gutiérrez (1977) esbozó su teología de la liberación y su invitación a hablar de Dios y la realidad desde el "reverso de la historia". En continuidad con esa tradición, exploro las nuevas situaciones de opresión y las prácticas de resistencia de los excluidos desatadas por la pandemia, interrogándolas desde el pensamiento decolonial. Concretamente, me detengo a examinar el éxodo de miles de ciudadanos, que desde Lima han retornado a sus lugares de origen, debido a las medidas de cuarentena. Interpreto esta inversión de las tendencias de migración interna en el Perú como un lugar para entender la violencia sistémica del actual sistema y reconocer las prácticas de supervivencia y solidaridad creadora de sus víctimas. Localizados desde esas historias de desesperanza y resistencia considero debemos empezar un examen sobre el Perú del bicentenario y la vigencia de la idea de la salvación cristiana.

\section{Precariedad de la vida, desplazamiento forzado y resistencia comunitaria}

En una inversión de las tendencias históricas de la migración interna en el Perú, decenas de miles de personas decidieron abandonar Lima $^{2}$ y otros centros urbanos para regresar a sus lugares de origen en el Perú rural. La motivación, a grandes rasgos, era que la cuarentena rígida decretada para impedir la propagación del virus había profundizado su condición de vulnerabilidad. La pérdida de empleo, el agotamiento de ahorros, el desalojo de sus viviendas y el hambre los obligaba a abandonar las ciudades, donde

1 Ver Ministerio de Salud del Perú, «Sala situacional COVID-19 Perú», https://covid19.minsa.gob.pe/sala_ situacional.asp

2 Lima es la capital de la República del Perú, el principal centro económico y la ciudad más poblada del país. De los 33 millones de peruanos, aproximadamente 10 millones viven en Lima. 
no contaban con redes de soporte familiar y los costos de vida eran infranqueables.

Este fenómeno requiere de categorías que permitan captar su especificidad. Según el teólogo José Luis Franco (2020), no estamos ante un caso de desplazamiento forzado interno, porque esa categoría jurídica se emplea para grupos de personas que son obligadas a escapar de su hogar y reubicarse en otro territorio dentro del propio país, es decir, sin cruzar una frontera internacional. ${ }^{3}$ En este caso, se trata, más bien, de un retorno al lugar de origen, en donde se invierte una trayectoria migratoria permanente o temporal. Franco, más bien, propone hablar de un "éxodo" y de identificar a los sujetos como "caminantes" que desafiaron a la autoridad estatal para sobrevivir.

Estoy de acuerdo con Franco que, en términos jurídicos, hablar de desplazamiento forzado interno en este caso, probablemente, sea impreciso. Sin embargo, considero que, desde una perspectiva ética y teológica, esta categoría permite captar y subrayar la violencia subyacente al éxodo de las ciudades al campo. Las razones por las que los "caminantes" o "retornantes" emprendieron sus travesías no fue el huir de un conflicto armado, pero sí de situaciones que ponían en riesgo sus vidas y representaban una violación a sus derechos fundamentales. Por tanto, respondió a una decisión que no obedecía a la libre voluntad del migrante, sino a un contexto adverso que los obligó a abandonar sus lugares de residencia habitual o temporal y realizar viajes arriesgados para refugiarse en sus pueblos de origen, donde se consideraban seguros.

Además, la raíz del problema era de carácter estructural: una economía que legitima condiciones de vida precaria y somete a millares a trabajos que apenas alcanzan para la subsistencia mínima. En varios casos, se trataba de personas viviendo por años en Lima y, aún a pesar de ello, no contaban con las condiciones para sobrevivir la cuarentena por sí mismos. Finalmente, hablar de desplazamiento forzado, también, permite subrayar las responsabilidades del Estado y la sociedad peruana con esta población, que, sin duda, constituyen uno de los rostros más vulnerables durante la pandemia y de los menos atendidos.

Hechas las precisiones conceptuales, procederéa analizar el fenómeno. La actitud inicial fue ver a los "caminantes" como un desacato a la autoridad y una trasgresión de las medidas de confinamiento social, que eran explicadas como una falta de conciencia respecto a la gravedad de la pandemia. Por tanto, el gobierno buscó impedir los desplazamientos con el soporte de las fuerzas policiales. Como argumenta Franco, tal posición, además de errada y simplista, reproducía la mirada centralista y sin empatía social que tiende a primar en el diseño de políticas públicas (2020, p. 45). Afortunadamente, el Estado cambió de estrategia al reconocer que lo que estaba en juego era una situación que visibilizaba la vulnerabilidad de un sector de la población ante las medidas de confinamiento social. Por tanto, se expidió

3 Al respecto la Agencia de las Naciones Unidas para los Refugiados (ACNUR) define el desplazamiento forzado interno como "toda persona o grupos de personas que se han visto forzadas u obligadas a escapar o huir de su hogar o de su lugar de residencia habitual, en particular como resultado o para evitar los efectos de un conflicto armado, de situaciones de violencia generalizada, de violaciones de los derechos humanos o de catástrofes naturales o provocadas por el ser humano, y que no han cruzado una frontera estatal internacionalmente reconocida". Ver https://www.acnur.org/prot/prot mig/5c6c3ae24/ manual-para-la-proteccion-de-los-desplazados-internos.html 
el Decreto de Urgencia No 043-2020, que facultaba a los gobiernos regionales emplear hasta 20 millones de soles para cubrir gastos de alojamiento y alimentación temporal de los "caminantes", además de habilitar espacios para que guarden la cuarentena respectiva.

En tanto el transporte interregional estaba suspendido, el Estado encargó a los gobiernos regionales registrar a las personas interesadas, gestionar el traslado y acondicionar espacios para la cuarentena en el lugar de llegada. Según cifras oficiales, en abril de 2020, eran más de 167 mil personas las que solicitaban el retorno, lo que desbordó los recursos económicos y de infraestructura de las entidades del Estado. Ante los altos números de retornantes, varios gobiernos regionales manifestaron sus limitaciones para acondicionar espacios públicos como campamentos de acogida o la falta de una infraestructura hotelera que pudiera ser puesta al servicio de esta situación.

Ante un Estado "fallido", incapaz de haber previsto este impacto social de las medidas de control sanitario y responder a la necesidad, las personas retornantes se sintieron abandonadas y decidieron organizarse para concretar su propósito. De tal manera, a través de redes de paisanos ${ }^{4}$ se organizaron grupos de WhatsApp para intercambiar información y recursos e, incluso, montar viajes de retorno. En tal sentido, durante abril de 2020, el Perú fue testigo de peregrinaciones de miles de familias trasladándose a pie hacia sus destinos. Tal éxodo humano generó la formación de campamentos improvisados para el descanso y el tránsito. En ocasiones agentes del Estado se hicieron presentes en estos sitios, pero incapaces de atender a todos, entraban a seleccionar a quienes se veían como más vulnerables para habilitar su atención preferencial.

Los testimonios de los retornantes, recogidos por el portal periodístico Ojo Público, revelan la crudeza de la hazaña (Red Investigativa Regional, 2020). El dormir a la intemperie, soportando frío y acechados por insectos o ratas, el pasar hambre, el soportar la hostilidad de la policía o de comunidades que se rehusaban a dejarlos pasar por sus territorios, el pagar cantidades exorbitantes para subirse a un camión y adelantar un trecho del camino son experiencias recurrentes en las historias de los retornantes. Las carreteras del Perú se convirtieron en un depósito de cuerpos basurizados y tratados como "muertos vivientes". Esta tragedia encontró su epítome en la historia de Maykol Pariona Carbajal, quien murió ahogado al intentar cruzar nadando el río Pampas. Había caminado desde Ica, región agroexportadora donde tenía un trabajo temporal, intentando volver con su familia en Cocharcas, Apurímac, ubicado a más de 500 kilómetros del punto de origen.

Estas historias nos hablan de una urgencia por escapar para sobrevivir. La desesperación es lo único que explica que el viaje se viera menos amenazante que quedarse en Lima u otros centros urbanos a merced del hambre y el abandono. Algo de eso captura el siguiente diálogo en uno de los grupos de WhatsApp, tomado del reportaje mencionado de Ojo Público:

"-Yo también estoy aquí, sola con mi bebita. A veces pienso

4 En el castellano peruano, paisano es la manera de referirse a una persona con quien se comparte el mismo lugar de origen. 
que la vida se nos agota, escribe una mujer desde uno de los campamentos improvisados que se construyó en la Carretera Central, para los que intentaban salir de Lima.

-No digas eso, sé que Dios nos va a sacar de esto. Soy padre soltero, no puedo con esto, pero tenemos que salir de aquí, le responde alguien".

No obstante, hay otro elemento que llama la atención de dicho diálogo. Entre estos cuerpos vulnerables, incluso sin conocerse cara a cara, brotaban vínculos de solidaridad y cuidado. La experiencia compartida del despojo y el abandono eran las fuentes que empujaban a formar comunidad para responder ante el sufrimiento con un espíritu resiliente.

A más de un año de este episodio, valdría la pena conocer a profundidad las historias de los retornantes como espacios de duelo y resistencia, así como rastrear la situación de esas comunidades forjadas entre carreteras y WhatsApp. Es posible que muchos hayan perecido en el camino por sobrevivir y sería un acto de justicia saber sus nombres, lamentar sus pérdidas y reparar a sus familiares. Por otro lado, la experiencia, ciertamente, ha dejado heridas que necesitan nombrarse y curarse en el seno del vínculo comunitario. No se puede pasar página sin conocer qué efectos han tenido en sus protagonistas y hacernos colectivamente responsables de este drama. Finalmente, es posible que esas comunidades de retornantes siguen vinculadas creando nuevas resistencias y solidaridades, lo que constituye una historia que debe ser narrada y visibilizada para refundar el Perú. Lamentablemente, no lo sabemos aun cuando deberíamos estar interesados en saberlo. Aquítenemos una de las tantas deudas pendientes para el Bicentenario de la fundación de la República.

\section{Las víctimas-sobrevivientes del desplazamiento forzado como lugar ético-teológico}

El desplazamiento forzado interno por la pandemia, aunque aún necesita ser reconstruido con mayor exhaustividad y empatía social, es un lugar desde donde pensar las implicancias profundas de la crisis estructural actual. Desde mi perspectiva, en las historias de las víctimassobrevivientes del desplazamiento forzado, hay un potencial narrativo para re-imaginar el Perú bicentenario desde un horizonte descolonizador. Siguiendo a la historiadora boliviana Silvia Rivera Cusicanqui, sus historias invitan a concebir un "mundo al revés" que exponga la criminalidad del orden social neoliberal y restaure los fundamentos éticos de un proyecto republicano (2020, p. 7). Los retornantes dan testimonio de luchas de resistencia ante la muerte, sin lugar a duda. Pero también exponen las deudas pendientes y los legados coloniales que el sistema hegemónico neoliberal silencia. No es casualidad que la migración de retorno hacia las regiones más vulnerables fue la que costó más trabajo no solo en atender, sino en gestionar dentro de sus regiones de destino. Concretamente, los gobiernos de Cajamarca (zona de conflictos sociales por la actividad minera), Ayacucho o Apurímac (de las más golpeadas por el conflicto armado interno, 1980-2000) tuvieron reducida capacidad de implementar el retorno (Ayala, 2020).

Asimismo, este evento cuestiona la imagen dicotómica de la ciudad como el sitio de progreso económico y seguridad, que es contrastado con el retrato del campo como el lugar de atraso y pobreza. 
La pobreza urbana no solamente es una realidad en ascenso durante los últimos años de boom económico, sino invisible a las políticas públicas y a los imaginarios nacionales que tienden a pintar las periferias de Lima como tierra de emprendedores exitosos (Maco, 2021). No es posible imaginar el Bicentenario sin atender las fracturas que ha revelado la inversión de las tendencias de la migración interna durante la pandemia.

Por lo dicho, las historias de desplazamiento forzado deben ser entendidas como una expresión de violencia sistémica y estructural. Como sostiene el filósofo peruano Miguel Giusti, la crisis sanitaria no es una "desgracia natural". Afirmar tal cosa conduce a una narrativa que invisibiliza la responsabilidad humana y neutraliza la crítica del sistema hegemónico (2020, pp. 174-181). Más bien, es imprescindible visibilizar las especificidades de estas violencias, atendiendo su carácter sistémico y visibilizando las interacciones entre colonialismo, patriarcado heteronormativo, economía extractivista y racismo.

Adicionalmente, no pueden interpretarse solo mirando el momento presente, sino que debe considerarse la pandemia como un episodio dentro de lo que Immanuel Wallerstein ha denominado la crisis del sistema-mundo moderno y la bifurcación hacia un nuevo mundo (2004, pp. 76-90). La tragedia de los desplazados forzados en el Perú, en muchos sentidos, es consecuencia de una economía global capitalista que se sustenta en un modelo de acumulación por despojo y precarización de la vida (Zibechi, 2020, pp. 11-23), que ha sido denominado por el papa Francisco como "cultura del descarte" en su encíclica Laudato Si'. Por tanto, no es posible comprender y resistir la crisis sanitaria sin reconocer que sus impactos son reforzados $\mathrm{o}$, incluso, originados, en una violencia sistémica y multidimensional enraizada en el status quo de la modernidad tardía.

En las historias de supervivencia de los "retornantes", hay un desafío a la fe cristiana y la teología en su permanente tarea de discernir los "signos de los tiempos" y animar una praxis histórica liberadora. De hecho, lo producido por teólogos peruanos durante esta crisis se ha orientado a sistematizar componentes de la tradición cristiana ofreciéndolos como claves para hacer una lectura contemplativa del momento actual y destacar los esfuerzos solidarios y transformativos desde la base social y las instituciones (Iberico, 2020; Pariamachi, 2020; Van der Maat, 2020; Zegarra, 2020). Pero ha adolecido de un diálogo más encarnado con las víctimas de la COVID 19 y otras pandemias sociales. Aun cuando los teólogos citados, influenciados por Gustavo Gutiérrez, sostienen que los pobres y las víctimas son un lugar teológico prioritario y fontal, sus voces, historias y cuerpos no aparecen en los textos de dichos autores.

Por ello, pienso que la pandemia y las violencias que ha agudizado no es solo un desafío pastoral al cual responder. Más bien, allí aparece un llamado a una conversión de la comunidad teológica hacia nuevas interrogantes, métodos y epistemologías, atendiendo las circunstancias históricas del siglo XXI y los giros del pensamiento teológico reciente. Solo así la producción teológica encarnará con mayor fidelidad histórica y sensibilidad que los oprimidos, en tanto sacramento de Dios en la historia, demandan historizar la promesa de salvación aquí y ahora como liberación de estructuras de opresión y cegueras 
sociales, convocando a toda la humanidad a sumarse a dicho movimiento salvífico.

Para Gustavo Gutiérrez, las preguntas teológicas que surgían de la realidad histórica peruana de los años 1970 y 1980 eran cómo hablar del amor de Dios en un mundo de injusticia y, particularmente, desde Ayacucho, el "rincón de los muertos" (Gutiérrez, 1986, 1988). Hoy, en el Perú de la pandemia, se podría decir que la interrogante es otra: cómo consolar a un pueblo en duelo enfrentando un "sociocidio" y, desde la solidaridad entre las víctimassobrevivientes, despertar una praxis liberadora que restituya la centralidad del cuidado de la vida. Aunque aún en modo provisional, quiero plantear algunas claves para interpretar teológicamente la experiencia de las víctimas-sobrevivientes del desplazamiento forzado desde el horizonte de un Perú descolonizado y resiliente ante la violencia sistémica y la inquietud por una teología con mayor sintonía con estos desafíos.

Primero, siguiendo a la teóloga mexicana-estadounidense Nancy PinedaMadrid (2011), ante un caso de esta magnitud, es necesaria una hermenéutica del sufrimiento como experiencia social, que devele las conexiones entre las experiencias privadas de muerte temprana y los intereses de poder que buscan manipular la realidad para imposibilitar cualquier forma de accountability. Y, como acto consecuente, comprender las prácticas de resistencia de las comunidades como "textos religiosos" que, a través de sus esfuerzos por subvertir comunitariamente el mal que los oprime, revelan la presencia fiel y el trabajo salvífico en marcha del misterio trinitario del amor. Una reflexión teológica comprometida con estas víctimas-sobrevivientes debe visibilizar las dinámicas de dominación presentes en los sufrimientos desencadenados por la pandemia y proclamar que las historias de supervivencia y solidaridad son terrenos donde somos testigos de la actualización del misterio pascual.

Para que tal horizonte sea posible es imprescindible situarse desde "el lado oscuro de la historia", como afirma el filósofo camerunés Achille Mbembe (2019), donde las dinámicas del necropoder se recrean en tiempos de pandemia generando nuevos cementerios y basurales donde yacen cuerpos descartados y olvidados por la economía de acumulación por despojo y la "militarización" de la vida. Es tal el caso de la inversión de tendencias de la migración interna en el Perú por la COVID-19, como grafican las historias referidas en la sección anterior. Como argumenta el historiador estadounidense Christopher Lee (2020), es clave reconocer que la pandemia implica una crisis de soberanía, ya que revela la incapacidad de los poderes estatales de atender asuntos no vinculados a las finanzas públicas.

Lo descrito por Mbembe y Lee lo vemos en el caso del Perú, donde un Estado que por dos décadas fue elogiado por la estabilidad de su macroeconomía y la salvaguarda de sus reservas fiscales, ha sido incapaz de responder ante la emergencia sanitaria. Las políticas de mitigación social no solo resultaron inefectivas o insuficientes por desconocer la complejidad de las realidades de las poblaciones vulnerables, sino además generaron este éxodo de las ciudades hacia el campo, cuya motivación fue el miedo al hambre. La COVID-19 ha expuesto los efectos corrosivos de las agendas neoliberales, que han convertido el poder soberano gubernamental en un árbitro de la muerte antes que en garante 
de la vida y el bienestar, como afirma Lee. Una teología desde el lado de las víctimassobrevivientes tiene que visibilizar este aparato corrosivo y las resistencias que emergen de quienes son afectados.

Finalmente, una teología que conecte con las víctimas-sobrevivientes de la pandemia necesita repensar algunas de las categorías que de facto aplica a su lectura de la realidad. Por ejemplo, en el caso del desplazamiento forzado, cometeríamos un abuso hermenéutico si hablásemos de una esperanza movilizando a los "retornantes". Al contrario, la desesperación y la desesperanza de saber que su vida estaba amenazada y que no tenían nada que perder se convirtió en un ímpetu hacia una práctica de supervivencia. Como apunta el eticista cubano-estadounidense Miguel de la Torre, ante experiencias de opresión sistémica, necesitamos abrir espacio para una teología de la desesperación y la desesperanza, porque es más fiel a la experiencia de las víctimas de estas tragedias. En sus palabras, la desesperanza no necesariamente conduce a la resignación, la inercia o la melancolía, sino para muchos oprimidos es "un acto de coraje para abrazar la realidad y actuar aun cuando todo apunta a una derrota" (De la Torre, 2017, p. 140).

Una opción preferencial por los pobres supone abrazar esta realidad y colaborar en que se transforme en una práctica de cambio radical que ponga en aprietos las estructuras opresivas (De la Torre, 2017, pp. 149 154). De alguna manera, los desplazados forzados testimonian esta posibilidad. La organización de sus peregrinaciones transgredió las normas gubernamentales, que les exigían permanecer donde estaban, pero sin garantizarles el sustento necesario para sobrevivir una cuarentena estricta sin ingresos $\mathrm{u}$ ahorros. Ante una norma inmoral, establecieron redes de solidaridad creadora y resiliente para desafiar al necro-Estado y sus medidas que los condenarían a la muerte temprana. Al final desbordaron al Estado y, como he intentado argumentar a lo largo de este ensayo, desnudaron la profundidad de las desigualdades y las insuficiencias del status quo neoliberal.

\section{A manera de conclusión}

Habría mucho más por decir, pero creo que mi punto ha quedado planteado. El caso de los desplazados forzados por la pandemia es un lugar desde donde imaginar un horizonte ético-político alternativo al sistema hegemónico y un discurso teológico comprometido con una praxis histórica de cambio social sustantivo y solidaridad con los oprimidos. Abrazar la desesperanza de las víctimas-sobrevivientes y testimoniar las prácticas de resistencia y supervivencia que despierta es una pista fundamental para pensar ética y teológicamente el Perú bicentenario y actuar hacia su reconstrucción. Es, además, una invitación a vincular a las víctimas de las múltiples violencias en una cadena de solidaridad que active prácticas de resistencia y cooperación que hermanen en un proyecto de auténtica fraternidad universal y transformación del mundo enfermo en que habitamos.

\section{REFERENCIAS BIBLIOGRÁFICAS}

Arroyo, P. (2020). Aciertos y fallas en la pandemia: ¿Posibilidad de un nuevo pacto social? Páginas, 45(259), 6-16.

Ayala, H. (2020, mayo 5). Desplazamiento forzado en tiempos de Covid-19: ¿qué hemos aprendido del posconflicto? 
Instituto de Democracia y Derechos Humanos. https://idehpucp.pucp. edu.pe/notas-informativas/ desplazamiento-forzado-entiempos-de-covid-19-que-hemosaprendido-del-posconflicto/

Comité de Alto Nivel sobre el COVID-19. (2021). Informe sobre las causas del elevado número de muertes por la pandemia del COVID-19 en el Perú. Lima: Consejo Nacional de Ciencia, Tecnología e Innovación.

De la Torre, M. A. (2017). Embracing Hopelessness. Minneapolis: Fortress Press.

Franco, J. L. (2020). COVID -19 y un nuevo éxodo en el Perú. Revista do CEAM, 6(1), 43-49. https://doi. org/10.5281/ZENODO.3953302

Giusti, M. (2020). Tiempo detenido. En G. Perona (Ed.), 25 ensayos desde la pandemia para imaginar el Perú bicentenario (pp. 174-181). Lima: Comisión del Bicentenario del Perú.

Gutiérrez, G. (1977). Teología desde el reverso de la historia. Centro de Estudios y Publicaciones.

Gutiérrez, G. (1986). Hablar de Dios desde el sufrimiento del inocente. Una reflexión sobre el libro de Job. Centro de Estudios y Publicaciones.

Gutiérrez, G. (1988). Cómo hablar de Dios desde Ayacucho. Revista Latinoamericana de Teología, 15, 233 241.

Iberico, R. (2020). Contemplación y compromiso. Una espiritualidad para tiempos de pandemia. Páginas, 45(259), 34-44.
Lee, C. (2020, abril 1). The Necropolitics of COVID-19: A Global South Approach to the Current Pandemic. Africa is a Country. https://africasacountry. com/2020/04/the-necropoliticsof-covid- 19

Maco, V. (2021, febrero 24). La desatención de la pobreza urbana en el Perú: ¿una paradoja frente a la experiencia latinoamericana? Noticias SER. https://noticiasser. pe/la-desatencion-de-la-pobrezaurbana-en-el-peru-una-paradojafrente-a-la

Mbembe, A. (2019). Necropolitics. Durham: Duke University Press.

Pariamachi, R. (2020). Religión y pandemia. Centro de Estudios y Publicaciones.

Pineda-Madrid, N. (2011). Suffering and Salvation in Ciudad Juárez. Minneapolis: Fortress Press.

Red Investigativa Regional. (2020, abril 26). La dura travesía de los más pobres: Pandemia y desempleo expulsan a miles de migrantes. Ojo Público. https://ojo-publico. com/1786/desplazados-por-lapandemia-la-travesia-de-los-maspobres

Rivera Cusicanqui, S. (2020). Ch'ixinakax utxiwa: On Practices and Discourses of Decolonization. Cambridge, UK: Politi.

Seminario, B., Palomino, L., E Pastor, G. (2020, mayo 8). Perú: Estimando el impacto macroeconómico de COVID-19. Foro Económico. https:// focoeconomico.org/2020/05/08/ 
peru-estimando-el-impactomacroeconomico-de-covid-19/

Taj, M., E Kurmanaev, A. (2020, junio 2). Virus Exposes Weak Links in Peru's Success Story. The New York Times. https://www.nytimes. com/2020/06/12/world/americas/ coronavirus-peru-inequalitycorruption.html

Van der Maat, B. (2020). Epidemias y religión. Revista de Teología, 23(48), 49-81.

Vergara, A. (2020). La crisis de la COVID-19 como Aleph peruano. En V. Pettina \& R. Rojas (Eds.), América Latina. Del estallido social a la implosión económica y sanitaria post-COVID 19. Lima: Crítica.
Wallerstein, I. (2004). World-Systems Analysis. An Introduction. Durham: Duke University Press.

Zegarra, R. (2020). ¿Mirar más lejos? Nuevas perspectivas para la teología de la liberación. Páginas, 45(259), 18-26.

Zibechi, R. (2020). Acumulación por robo y violencia sistémica. Concilium, 384, 11-23.

Fecha de recepción: 01/09/2021

Fecha de aceptación: 27/09/2021 